\title{
CONCEPTUAL FRAMEWORK FOR THE WATER USE BENEFIT INDEX IN THE GREAT BARRIER REEF REGION
}

\author{
S. LARSON \& A. SMAJGL \\ CSIRO Sustainable Ecosystems, Townsville, Queensland, Australia.
}

\section{ABSTRACT}

In this paper, an initial conceptual framework for the development of a performance indication tool for water use in the Great Barrier Reef region is described. The tool is envisaged as a simple, cost-effective and informative tool for indication of the temporal and regional performance. It is intended for use by non-technical target groups, such as the general public and the local government, and is proposed to be presented as an internet-based index. The index is proposed to cover objectives in the areas of physical-chemical, biological and socio-economic primary and secondary aspects of water use and benefits derived from its use. Each aspect is proposed to consist of not more than five indicators. It is clear that this number of indicators cannot provide a full and comprehensive picture of water use and benefits to the region, but rather an overview of the performance trends. To reinforce this understanding, the index results are proposed to be presented as letters rather than absolute numbers, which represent ordinal 'scores'. This approach would also allow for comparison across a variety of indicators and the units they are measured in. The paper also presents a brief overview of the types of indicators currently used for the assessment of water-related attributes and the methods of their aggregation.

Keywords: water benefits, index construction, Great Barrier Reef, ordinal scores, performance indicators, water use.

\section{INTRODUCTION}

Under international environmental law, the right to a healthy environment has received increased recognition. This right includes various substantive elements such as the right to food and water, the right to preservation of soil and water, and the right to adequate standards of living and health. These rights are determined by several international declarations and conventions such as the Universal Declaration of Human Rights, the Convention on the Elimination of all Forms of Discrimination against Women and the Convention on the Rights of the Child. Similar developments have occurred in the area of freshwater management. The 1992 International Conference on Water and the Environment adopted a statement acknowledging 'the basic right of all human beings to have access to clean water and sanitation at an affordable price'.

The right to a healthy environment has received further attention through the Sustainable Development Goals in Agenda 21. It is accepted that sustainability is not a process that could emerge on its own from the economic development process, but rather requires focused attention on the part of governments, the private sector, communities and individual citizens. Although some international studies find that sustainability does broadly correlate with per capita income, the level of development does not imply nor ensure desirable environmental and social circumstances [1].

Complex suites of environmental, social and economic indicators have been developed. The indicators in those suites are most often used independently, typically to analyse the performance of geographic areas, companies, projects or policies. More recently, a combination of indicators across the 'triple bottom line' has been used as a means of measuring progress towards and away from sustainability $[2,3]$.

Water, water benefits and water allocations are currently receiving much attention from Australian policy makers. There is a perceived need for the development of tools that could generate recommendations for improved governance mechanisms to link geographical scales and bridge sectoral divides, while sustaining both human livelihood and biological diversity. One of the tools that would merit 
development in this context is a simple and cost-effective tool that would target general stakeholders, an audience characterised by varied levels of education, comprehension, technical capabilities and time available.

This paper presents a brief overview of the types of indicators currently used for the assessment of water-related attributes and the methods of their aggregation. It then investigates a conceptual framework for the development of a simple, cost-effective assessment and benchmarking tool for temporal and spatial indication of sustainability trends of water use in the Great Barrier Reef region of Queensland, Australia.

\section{INDICATORS IN THE CONTEXT OF WATER USE}

\subsection{Selection of indicators}

The framework developed by the Organisation for Economic Co-operation and Development uses three basic criteria for the selection of indicators: policy relevance, analytical soundness and measurability [4]. The basic set of principles that good policy indicators need to comply with has been summarised by Jiménez-Beltrán [5] as:

- Indicators should report progress over time and be linked to specific policy questions, i.e. should be accompanied with an explanation of the reasons for their development.

- Indicators should be few in number, and users should become familiar with their presentation and explanation of the signal they give as well as its significance.

- Indicators become more powerful when linked with formal targets or informal or indicative reference values. When linked with targets, indicators become tools for management and for making policy makers and implementers accountable.

- With or without targets, both failure and success stories become evident when using indicators to compare or benchmark individual sectors or countries/regions or companies with each other. This is another way to make decision makers and implementers accountable and to foster progress, as exposing this kind of information to the outside world can lead to 'peer pressure' to do better.

In addition, indicators need to be feasible to measure and obtain in a cost-effective manner on a regular basis, scientifically credible and collected using a systematic method.

Indicators can be broadly classified into the following types:

- Performance indicators: indicators including or linked with quantifiable policy targets, providing a precise assessment of progress made; targets can be international, national or set by voluntary codes of conduct;

- Descriptive indicators: indicators showing the trajectory of a variable, but either connected to a qualitative target ('to increase', 'to stabilise') or not having a set policy target;

- Eco-efficiency indicators: indicators linked to specific sectoral targets, processes and product use.

Until recently, the majority of indicator measures for any of the aspects of sustainable development were objective measures. These represent frequencies or quantities of a particular objective that can be repeatedly verified by any number of persons. However, they fail to measure how people feel about those objectives or what the perceived compliance with the target is. To achieve this, subjective indicators have increasingly been used, starting with areas such as the subjective quality of life [6], and have also been used to evaluate perceptions on environmental quality and assign weights to environmental parameters [7]. 
For indicators to be relevant in the regional context, they have to focus on those issues that a region, or a regional development project, can control or influence. Birkmann [8] argues, furthermore, that in order to reflect the practical requirements and application, indicators should only measure key elements instead of trying to indicate all aspects. In the context of regional development, sustainable development indicators are used for two main purposes [4]:

- to monitor the development of the region, with regional planners, state and regional authorities, businesses, NGOs, and the general public as target groups;

- for project and programme selection and monitoring, with the project managers, programme managers and monitoring committees as the main target groups.

\subsection{Indicators of water attributes}

In order to measure the performance and actions related to water, a set of indicators allowing measurement of trends in water use and benefits needs to be developed. This section compares some of the examples of the types of indicators used in the assessment of water quality, water quantity and water benefits, both in Australia and internationally.

\subsubsection{Moreton Bay Ecosystem Health Index}

One of the most comprehensive water-specific sets of indicators developed to date in Australia is the Ecosystem Health Index (EHI) developed for the Moreton Bay area in Queensland [9]. The index was created as a response to the implementation of the South East Queensland Regional Water Quality Management Strategy. The index monitors impacts of the management actions, undertaken under the strategy, on the regional ecosystems' health. The index is divided into a freshwater component and an estuarine/marine component. Freshwater indicators are grouped into areas of ecosystem structure, ecosystem function and water quality measures. Estuarine and marine indicators are grouped into physical and chemical attributes, nutrients and other indicators, such as Cyanobacterium and coral monitoring. The indicators used in the EHI assessment are presented in Table 1, as a comparative list to other water-related indicator sets.

\subsubsection{Europe's water}

The European Environmental Agency (EEA) has adopted the DPSIR (Drivers-Pressures-State-ImpactResponses) framework as a standard methodology for the development of sustainability indicators. The DPSIR framework represents a systems analysis view of the relations between the environmental system and the human system. The framework is based on the premise that social and economic activity exerts pressure on the environment, causing changes in the state of the environment. These may lead to impacts that require a response. The response modifies the driving forces, reducing pressure and impacts [10]. A generic DPSIR framework developed by EEA for water is presented in Fig. 1.

The framework serves as a reference point for the selection of water-specific issues. The issues are then presented in relation to the relevant policies and related policy objectives, and a specific DPSIR is developed for each issue. These lead to specific policy-relevant questions, which are answered using the identified indicators.

The four issues addressed in the EEA Water Assessment [10] are: ecological quality, nutrients and organic matter, hazardous substances, and water quantity.

An abbreviated list of the EEA indicators for water is presented in Table 1. 
Table 1: Comparative lists of selected water-related indicators.

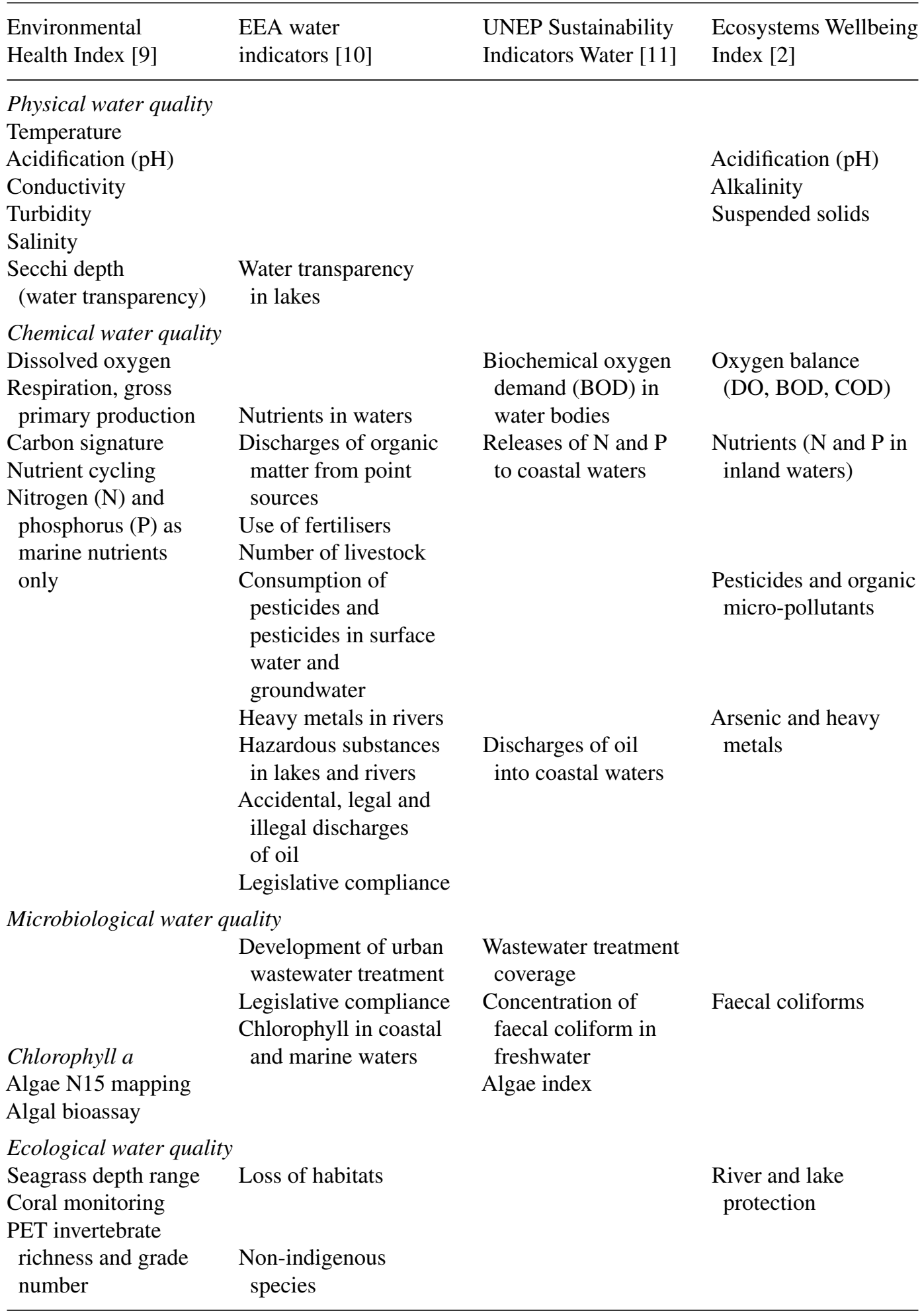


Table 1: Continued

\begin{tabular}{|c|c|c|c|}
\hline $\begin{array}{l}\text { Environmental } \\
\text { Health Index [9] }\end{array}$ & $\begin{array}{l}\text { EEA water } \\
\text { indicators [10] }\end{array}$ & $\begin{array}{l}\text { UNEP Sustainability } \\
\text { Indicators Water [11] }\end{array}$ & $\begin{array}{l}\text { Ecosystems Wellbeing } \\
\text { Index [2] }\end{array}$ \\
\hline $\begin{array}{l}\text { Fish native species } \\
\text { richness }\end{array}$ & $\begin{array}{l}\text { Environmental impact } \\
\text { of fishing }\end{array}$ & & \\
\hline $\begin{array}{l}\text { Fish assemblage, } \\
\text { percentage of alien } \\
\text { individuals }\end{array}$ & $\begin{array}{l}\text { Biological effects } \\
\text { of hazardous } \\
\text { substances on aquatic } \\
\text { organisms }\end{array}$ & $\begin{array}{l}\text { Maximum sustained } \\
\text { yield for fisheries }\end{array}$ & \\
\hline Cyanobacterium & $\begin{array}{l}\text { Hazardous substances } \\
\text { in marine organisms } \\
\text { Legislative compliance }\end{array}$ & & \\
\hline \multicolumn{4}{|l|}{ Water quantity } \\
\hline & Groundwater levels & Groundwater reserves & \\
\hline & $\begin{array}{l}\text { Available water } \\
\text { Water exploitation } \\
\text { index }\end{array}$ & $\begin{array}{l}\text { Annual withdrawal of } \\
\text { water }\end{array}$ & \\
\hline & $\begin{array}{l}\text { Total water abstraction } \\
\text { Water consumption } \\
\text { index }\end{array}$ & $\begin{array}{l}\text { Domestic consumption } \\
\text { of water per capita }\end{array}$ & $\begin{array}{l}\text { Water withdrawal as } \\
\text { a percentage of } \\
\text { the supply }\end{array}$ \\
\hline & Sectoral use of water & & \\
\hline & Agricultural water use & & \\
\hline & $\begin{array}{l}\text { Water use by } \\
\text { households }\end{array}$ & & \\
\hline & $\begin{array}{l}\text { Overall reservoir } \\
\text { stocks }\end{array}$ & & \\
\hline & Saltwater intrusion & Density of & \\
\hline & Water prices & hydrological & \\
\hline & Water use efficiency & networks & \\
\hline & Water leakage & $\begin{array}{l}\text { Population growth in } \\
\text { coastal areas }\end{array}$ & River conversion \\
\hline
\end{tabular}

2.2.3 United Nations' sustainability indicators

Following the 1992 Rio Conference, the United Nations Environment Programme (UNEP) developed a series of indicators designed to determine governmental progress towards sustainable development goals. The selection of sustainability indicators is based broadly on the sections of Agenda 21 and falls into four categories: social aspects, environmental aspects, economic aspects and institutional aspects. Environmental aspects contain issues related to water, land, atmosphere and waste [11]. The UNEP indicators related to water are presented in Table 1.

2.2.4 The Wellbeing of Nations Index

The Wellbeing of Nations Index [2] lists water indicators under the Ecosystem Wellbeing Index, with the main water objective being maintenance or restoration of major aquatic ecosystems with minimum loss of communities and habitats within them and minimal stress from pollution and 


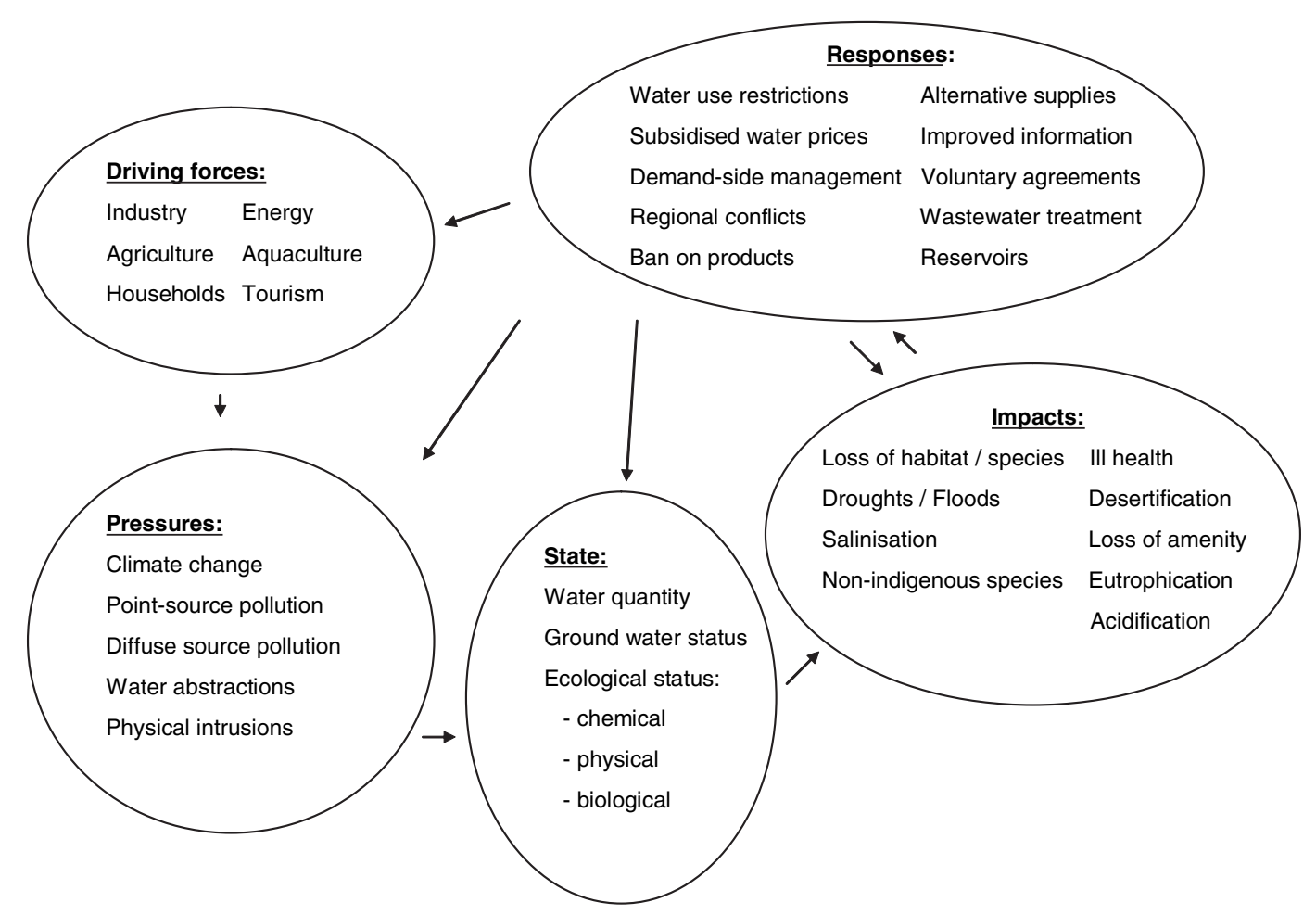

Figure 1: EEA's DPSIR framework for water [10].

water uses. The water indicators are grouped into three main groups: inland water quality, inland water diversity and water withdrawal. The indicators used in this assessment are summarised in Table 1.

\subsection{Methods of indicator aggregation}

In order to overcome the problem of each indicator conveying signals about particular elements but not about the system, indicators need to be combined into an integrated index. For this index to function, common units that would allow for comparison of 'apples and oranges' need to be found [2]. Recent work to produce indicators of sustainability has succeeded at aggregating individual indicators so that they respond to the demands for measure of overall sustainability trends. Some of the examples from the recent literature are presented here, as well as the EEA concept of 'headline indicators'.

\subsubsection{Environmental Sustainability Index}

The Environmental Sustainability Index (ESI) developed by the World Economic Forum is a measure of the overall progress towards sustainability that compares 142 countries [1]. The variables in this index are standardised into a unitless scale based on the $z$ score, which is a score that always has an average of zero, and the state of an indicator is measured as the distance from its baseline condition of zero. The formula used to calculate the $z$ score is the value of the variable minus the mean of the variable divided by the standard deviation. For variables in which high observed values correspond to low values of environmental sustainability, such as 'percentage of mammals threatened', the $z$ scores 
were inverted so that the higher percentage gave a lower score. Overall, zero indicates the mean, +1 and -1 represent one standard deviation above and below the mean, +2 and -2 represent two standard deviations above and below the mean, and so on. The component scores are presented as standard normal percentiles, ranging from a theoretical low of 0 to a theoretical high of 100 . The data for each country is presented as a cluster overview of five key components of the index: environmental systems, reducing stress, reducing human vulnerability, social and institutional capacity, and global stewardship.

Each variable receives equal weight. The authors argue that, if the underlying processes were fully understood, they would almost surely support an algorithm of unequal weighting, with differential weights derived from the different degrees of impact on overall environmental sustainability. However, they found no firm basis for applying differential weights given the current state of scientific understanding and the high likelihood that scientific consensus about the relative contributions of different factors to sustainability is not going to be reached any time soon.

\subsubsection{The Wellbeing of Nations}

The Wellbeing of Nations Index [2] approach uses performance scores as a common unit for comparison of the various types of indicators measured. Indicator performance is presented on a $0-100$ scale separated into five equal (20\%) bands, from 'bad' (0-20) to 'good' (80-100). The aggregated index score is based on the lowest score of indicators being combined. In the case of water, for example, the lowest score out of river conversion, water quality and water withdrawal scores is taken to indicate the overall country performance. As a result, Australia, for example, has a 'poor' overall score due to its 'poor' ranking for the inland water quality index, regardless of 'good' scores for both the river conversion and the water withdrawal indicators.

\subsubsection{Moreton Bay EHI}

Water quality objectives for the EHI [9] associated with each indicator are set based on geographical or historical reference. Annual median values are calculated for each monitoring site and spatial interpolation is mapped. Within each reporting zone, the area of the zone that complies with the water quality objective is calculated and referred to as the 'compliant area'.

Report cards are also derived for the areas. The Freshwater Report Card Eco-H-plots are standardised for five main indicator components: fish, invertebrates, ecosystem processes, nutrients and physical/chemical characteristics; and the Estuarine and Marine Report Card is based on total phosphorus, turbidity, chlorophyll a and total nitrogen.

\subsubsection{Headline indicators}

The environmental headline indicators concept is based on the provision of simple and clear information to decision makers and the general public about the key factors determining the state of the environment and progress towards sustainability [12]. Sets of headline indicators are proposed to contain not more than 10 indicators.

The headline indicators concept is based on the data pyramid approach. The pyramid sits on a broad base of disaggregated, detailed raw data obtained through the auditing or monitoring process that, with rudimentary processing, is compiled into a set of specific indicators. Writing in the context of nationally based indicators of sustainability, Mitchell [13] has suggested that this primary set of specific indicators is suitable mainly for use by the scientific community. From these specific indicators, a smaller set of composite indicators can be developed by aggregating data sets to produce information that can be conveyed to those with some technical and scientific knowledge but no 
familiarity with specific details, such as senior management or government agencies. At the top of the pyramid is a small set of key indicators, headline indicators, intended for use by the general public.

Each area of sustainability is proposed to have its own set of headline indicators, collation of which covers all sustainability issues. The headline indicators are not, however, additive in any way.

\section{CONCEPTUAL FRAMEWORK FOR THE WATER USE BENEFITS INDEX}

This section presents the initial conceptual framework for the development of an assessment and benchmarking tool for indication of sustainability trends of water use in the Great Barrier Reef region of Queensland, Australia. The objective of the tool is to allow for temporal and spatial comparison of performance trends in the region, with the general public, the local government and agencies as the envisaged target audiences.

Three main objectives were set for the development of the tool, resulting in a set of principles to be taken into account while developing it (Table 2). In addition, the following general principles have been established:

- As improved performance in one of the dimensions of sustainability may negatively impact performance in other dimensions, the tool would need to provide multidimensional signals.

- Although the main target of the tool is water, objectives related to water benefits included in the index should also indicate human livelihood and biological diversity links with water.

Table 2: Objectives and resulting principles for the development of the water use benefits index.

Objective Principles recommended

1. Comprehensive tool: Development has to take into account specific demographic characteristics of the geographical area it is targeting, in particular target audiences' level of education, comprehension and available time.

2. Cost-effective tool: All steps of the project, from data collection through index collation to updating and maintenance, have to be simple and cost effective.

3. Informative tool: The index should provide a concise message to the reader a single glance, with the option of easily accessing deeper levels of information if required. The index is an informative and not a definite tool.
- Concise set of indicators using comprehensive language

- The index should be presented at several levels of complexity

- Each area of sustainability should be represented by a maximum of five indicators

- The signal the index gives and its significance should be provided in a user-friendly way

- The index should only use data that is readily available to stakeholders

- The index needs to be automated so that updates are quick and simple

- The index should be presented in an easily interpretable interface

- The index should be informative at each level of complexity

- The index should start with an overall picture and progress with links into details, allowing comprehension in different time frames

- The index should preferably use letters and not numbers, so as to avoid over-reading of the results, but still give a clear trend message 
- Indicators should report progress over time and should be linked to policy questions/targets, including those listed in the Reef Water Quality Protection Plan [14].

- The index can be used to compare or benchmark individual regions over time and to each other.

- Indicators need to be scientifically credible.

3.1 'Wish list' of the water use benefits indicators

Setting of the descriptive target objectives was a next step in the development of the index. The objectives were then paired with a 'wish list' of suitable indicators of progress towards the objective (Table 3).

Table 3: 'Wish list' of performance objectives with corresponding indicator of a trend.

\begin{tabular}{ll}
\hline Objectives for performance areas & Potential indicator \\
\hline Physical and chemical & \\
Improving the water quality & Physical: total suspended solids \\
& Chemical: heavy metals \\
& Chemical: nutrients \\
& Chemical: pesticides \\
& Microbiological: coliforms \\
& Groundwater abstraction \\
Safeguarding sufficient & Water bodies with unacceptably low flows \\
water quantity & Users' satisfaction with the water quality \\
Satisfying the needs of the users & \\
Biological & Change in the extent of protected habitats \\
Protecting habitats and species & Status of priority species \\
& Presence of non-indigenous species \\
Improving the management and & Fish stocks in immediate waters \\
conservation of fish stocks & Fish stocks in open waters, as nursery habitat indication \\
Funding protection and & Annual funding for natural resources management and \\
law enforcement & legislative enforcement \\
Public satisfaction with the state & Public satisfaction with the abundance of aquatic \\
of the aquatic environment & species \\
& Public satisfaction with the protection status of dugongs, \\
whales and dolphins \\
Social and economic & Diversity and abundance of recreational fishing species \\
Affordable supply & Income/turnover spent on water charges \\
Efficient water use & Water use per capita \\
Prosperous people and society & Water use per dollar of production \\
& Price of water to agriculture/other industry ratio or \\
price of water to agriculture/households ratio \\
Percentage unemployment \\
Primary versus tertiary sector employment ratio \\
Incidences of water-related diseases \\
collated by the Australian Bureau of Statistics (ABS) \\
\hline
\end{tabular}


The objectives were developed for the four sustainability dimensions of water: physical, ecological, economic and social. Most of the 'water' indicators in the literature are presented as a part of the broader set of sustainability indicators and therefore need to address only direct water attributes, i.e. water quality and quantity. This index is envisaged as a stand-alone tool, and therefore needed to include some measure of broader biological, social and economic aspects of water use and benefits.

\subsection{Index structure}

The index is envisaged to be presented as an internet-based tool consisting of several levels of information. The first level should be an at-a-glance comprehensive and informative overview of performance and trends in the catchments of the Great Barrier Reef region (Fig. 2).

The stakeholders could, if interested, proceed to the next level which would present an overview of a selected catchment or local area (Fig. 3). The overall index would be broken down into three main performance areas - physical, biological and socio-economic - and would display both current and previous rankings of the region in each performance area.

By clicking on a performance area, a stakeholder would be taken to the next level, where all the indicators selected for the particular performance area as well as their temporal trend and absolute

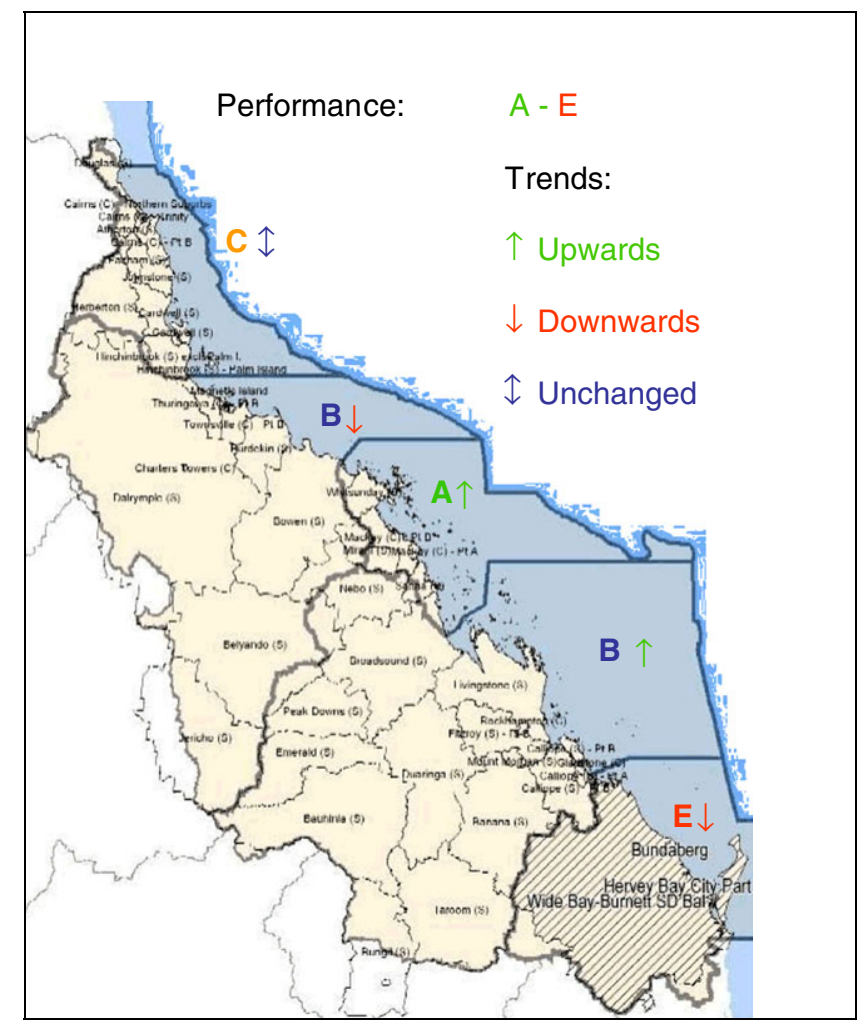

Figure 2: Proposed first level of the index covering catchments in the Great Barrier Reef region. (The scores presented here are only an example of the possible distribution and are not based on the performance data of the regions.) 
values would be displayed. Each indicator would be linked to another page that would contain a description of the indicator, what it is an indicator of, international standards, acceptable values and targets, and the methods used for data collection and analyses, etc.

One of the principles of the index is that it is an informative and not a definite tool. In order to avoid over-reading the values in the index, a lettered rather than a numbered approach to displaying is used. The approach is based on a 0-100 scale divided into equal quintiles. Each quintile is assigned a letter from $\mathrm{A}$ for the best performance to $\mathrm{E}$ for the poorest performance.

Trend movements are indicated by arrows placed after the letter, with upward pointing arrows indicating improved performance trends and downward pointing arrows indicating lowered performances.

\subsection{Index development}

The conceptual framework proposed for the development of the water use benefit index is planned to be tested and validated against actual performance data of the region.

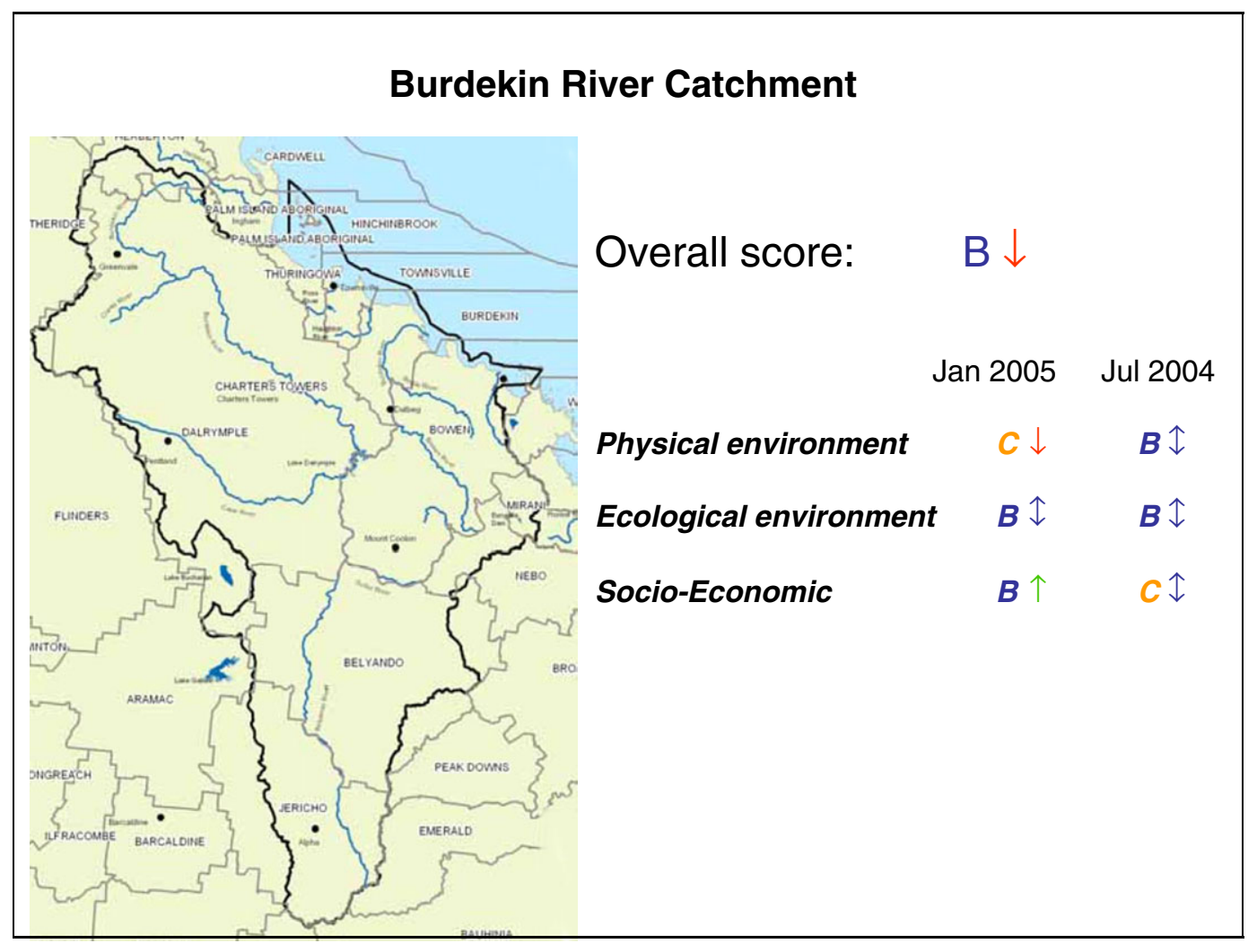

Figure 3: Proposed second level of the index providing physical, environmental and socio-economic temporal information of a selected catchment. (The scores presented here are only an example of the possible distribution and are not based on the performance data of the catchment.) 
The next step proposed in the development of the index is a reduction of the 'wish list' into a set of indicators that can be collated from data currently available. This set of indicators is being collated from the information available from the ABS and other major commonwealth and state agencies and bodies. Data is being collected for a minimum of two time-points, in order to allow for the initial temporal performance comparison and the validation of the temporal comparison concept.

Following the data gathering stage, data collated will be consolidated and an assessment will be made in order to ensure that all performance objectives are represented in the final data set at the catchment scale. For the indicator set to be functional, each performance objective will need to be represented by at least one populated indicator, and no performance objective area will be represented by more than five indicators. In the case that no suitable data sets are identified for any of the potential indicators of the set objective, a decision will be made to either reassess the objective or seek other, more costly and time-consuming avenues such as primary data collection.

Once collated, the final set of indicators in the water use benefit index will be compared and assessed against the other similar indicator sets used in other geographical areas.

Two approaches to ranking of the performance areas will be tested for their sensitivity:

- The first approach will use aggregation based on the mean result of all the indicators in the performance area, with the overall index based on the mean of the performance areas.

- The second approach will be based on the lowest indicator score in the performance area, and the index will present the lowest score of the three performance areas.

The decision on the approach to be used for the index collation will be made based on this sensitivity testing. This step of the index development should result in sufficient data to enable generation of the catchment-scale web output, similar to that proposed in Fig. 3. The next step of the index development will be an aggregation of all the catchment-level scores. The aggregated scores will be presented at the level of the Great Barrier Reef region, providing a web output similar to that proposed in Fig. 2.

In the conceptual framework proposed in this paper, the index is envisaged as a set of descriptive indicators. The indicators would show the development of the variables over time, but would not have quantitative but rather qualitative policy targets. The policy target approach will be re-visited during the index development stage and further investigated in comparison to 'return to natural state' and 'critical point' approaches. The main objective for the approach selection would be its capacity for allowing cross-catchment comparison.

The set of the above-proposed index development steps, i.e. data collection, aggregation and concept validation, is expected to result in a final concept of the water use benefit index. Once finalised, the index is planned to be placed on a public web site, and the new data sets should be uploaded on a semi-annual basis. The second level of the web site, based on individual catchments, and first level overall trends, will be updated to provide a temporal comparison between the performance of the latest and the immediate previous area.

\section{CONCLUSIONS}

This paper describes an initial conceptual framework for the development of a simple, cost-effective and informative tool for indication of the temporal and catchment performance related to the water use in the Great Barrier Reef region. The tool is intended for use by non-technical target groups such as the general public and the local government.

The tool is proposed to be presented as an internet-based index. The index would cover objectives in the areas of physical-chemical, biological and socio-economic primary and secondary aspects of water use and benefits. Each aspect is proposed to consist of not more than five indicators. It is clear that this number of indicators cannot provide a full and comprehensive picture of water use and benefits 
to the region, but rather an overview of the performance trends. To reinforce this understanding, the results would be presented as letter quintiles rather than absolute numbers. The letters would also allow for comparison across a variety of indicators and the units they are measured in.

The proposed set of indicators is being collated for a minimum of three time-points, from the information available from the commonwealth and state level agencies and bodies. Data collection and index population are conducted on the catchment level. Catchment-level assessment of the performance should allow for the inter-regional and inter-temporal comparison of time series, thus enabling the use of the tool as a preliminary-level decision-making support tool.

In order to assess its reliability and potential for a wider use, the index findings will be critically compared with other existing monitoring and tracking tools and methodologies used in the region.

\section{REFERENCES}

[1] World Economic Forum Global Leaders of Tomorrow Environment Task Force, Environmental Sustainability Index, World Economic Forum, Yale Center for Environmental Law and Policy and Center for International Earth Science Information Network Columbia University, Annual Meeting, 2002.

[2] Prescott-Allen, R., The Wellbeing of Nations, Island Press: Washington, Covelo, London, pp. 74-80, 2001.

[3] Warhurst, A., Sustainability Indicators and Sustainability Performance Management. Mining, Minerals and Sustainable Development, Project Report Number 43, International Institute for Environment and Development, 2002.

[4] Olsson, J.A., Bradley, K., Hilding-Rydevik, T., Ruotsalainen, A. \& Aalbu, H., European Indicators for Sustainable Development. Regional Network on Sustainable Development Discussion paper, Västmanland, 21-23 June 2004.

[5] Jiménez-Beltrán, D., Making sustainability accountable: the role and feasibility of indicators. From Gothenburg to Barcelona. Implementing the EU Sustainable Development Strategy, Brussels, 9 July 2001.

[6] Cummins, R.A., Eckersley, R., Pallant, J., Van Vugt, J. \& Misajon, R., Developing a national index of subjective wellbeing: the Australian unity wellbeing index. Social Indicators Research, 64, pp. 159-190, 2003.

[7] Hajkowicz, S., Multi-attributed environmental index construction. Ecological Economics, 57, pp. 122-139, 2006.

[8] Birkmann, J., Measuring sustainable spatial planning in Germany: indicator based monitoring at the regional level. Built Environment, 29(4), pp. 296-305, 2003.

[9] Ecosystem Health Monitoring Program, 2002-2003 Annual Technical Report, Moreton Bay Waterways and Catchments Partnership: Brisbane, 2002.

[10] Nixon, S., Trent, Z., Marcuello, C. \& Lallana, C., Europe's Water: An Indicator-Based Assessment, European Environmental Agency: Copenhagen, 2003.

[11] Consultative Group on Sustainable Development, Dashboard of Sustainable Development Dataset, Consultative Group on Sustainable Development Indicators, 9 January 2002.

[12] European Environment Agency Working Group on Monitoring, Indicators and Reporting Working Group 5, EU headline biodiversity indicators. Stakeholders' Conference on Biodiversity and the EU - Sustaining Life, Sustaining Livelihoods, Malahide, Ireland, 25-27 May 2004.

[13] Mitchell, G., Problems and fundamentals of sustainable development indicators. Sustainable Development, 4(1), pp. 1-11, 1996.

[14] Queensland Government, Reef water quality protection plan, Department of Premier and Cabinet, October 2003. 